\title{
NUMERICAL SIMULATION OF OPERATION PROCESSES IN THE COMBUSTION CHAMBER AND GAS GENERATOR OF OXYGEN-METHANE LIQUID ROCKET ENGINE
}

\author{
G. P. Kalmykov, A. A. Larionov, D. A. Sidlerov, \\ and L. A. Yanchilin
}

The results of numerical simulations of processes in gas generators and combustion chambers operating on oxygen and methane are presented. Specific features of mixing, evaporation, and combustion of propellants have been investigated. The degree of combustion completeness in chambers with three types of injectors - coaxial-jet gas-liquid, liquid-liquid monopropellant, and bipropellant impinging-jets injectors — has been estimated.

\section{INTRODUCTION}

At Keldysh Research Center (KeRC), a mathematical model, numerical method, and computer code for computational modeling of two-phase axially symmetric and three-dimensional turbulent reactive flows in liquid rocket engine (LRE) combustion chambers and gas generators have been developed [1]. The mathematical model is based on the Navier-Stokes equations and the $k-\varepsilon$ turbulence model. The combustion rate is defined by the model of turbulent vortex dissipation and by the generalized equation of chemical kinetics of the Arrhenius type. Droplet motion, heating, evaporation, and breakup are modeled using the Lagrange approach. The mass, momentum, and energy exchange between gas and droplets is modeled with due regard for turbulent flow characteristics. The equations are discretized using the control-volume method and solved utilizing the algorithm of the SIMPLER type $[2,3]$.

This methodology is widely used at KeRC for numerical simulation of the operation process in subscale and full-scale combustion chambers and gas generators with a variety of injectors fed by different propellants. 


\section{GAS GENERATOR WITH COAXIAL-JET INJECTORS}

To optimize the injector design for oxygen-methane gas generator, the numerical simulation of the operation process in a Mascotte research chamber with a single injector has been performed. The capabilities of the Mascotte test bench are described in [4-7]. Two variants of the coaxial-jet bipropellant injector were studied. In both variants, liquid oxygen $\left(T_{\mathrm{O}_{2}} \approx 90 \mathrm{~K}\right)$ was fed through the central cylindrical channel whereas gaseous methane $\left(T_{\mathrm{CH}_{4}} \approx 290 \mathrm{~K}\right)$ was supplied through the outer annular channel. Turbulence intensity of the methane jet at the inlet was specified as $u^{\prime} / U=7 \%$. The turbulence length scale was taken as $7 \%$ of the channel width. Inside the boundary layers, the following dependences were used: $U=U_{0}\left(y_{1} / \delta\right)^{1 / 7}$ and $\tau_{W}=\left(0.058 / \operatorname{Re}_{x}^{0.2}\right)\left(\rho U^{2} / 2\right)$. The mean diameter of drops in the LOX spray injected in the combustion chamber was estimated using dependences from [8]: $d_{\mathrm{O}_{2}} \leq 0.02 \mathrm{~mm}$. The diameters of the 1 st and 2 nd injector variants were $d_{K}=5.8$ and $9 \mathrm{~mm}$, respectively. The axisymmetric grid $\sim 200 \times 80$ was used. Below, the results of calculations are discussed.

Variant 1. The calculation was made at the pressure in the combustion chamber $P_{0}=60$ bar and mixture ratio $K_{m}=0.3$. In this variant, the oxygen injector nozzle had the depth $\Delta H=4 \mathrm{~mm}$ with respect to the outlet edge of the methane nozzle.

In Fig. 1, the near-axis part of the flow core element is occupied by oxygen spray. Flame is stabilized in the zones of reverse flows outside the edges of the oxygen nozzle. The narrow high-temperature zones approximately coinciding with the regions where $K=K_{\text {st }}$ extend downstream from edges of the oxygen channel between oxygen and methane streams. As a result of oxygen evaporation and combustion in the injector channel, the maximum velocity of gas flow at the inlet to the combustion chamber $(x=0)$ slightly increases. The toroidal recirculation zone adjacent to the combustion chamber bottom forms at the periphery of the element (Fig. $2 a$ ). It covers the gas generator jet running from the injector externally. The composition and temperature of gas phase in this zone are sufficiently uniform. The calculated value of the flame length (by the maximum temperature on the axis) comprises $54 \mathrm{~mm}$. Figure $2 b$ presents the experimental results of combustion process visualization in the Mascotte research chamber [8] with the injector of variant 1 for the operation parameters close to those specified in the calculations. The estimation based on these data gives the flame length of about $50 \mathrm{~mm}$ which corresponds well with the predicted value. Note that the variation of the initial mean diameter of oxygen drops in the range $\bar{D}_{\text {drop } 0}=20-40 \mu \mathrm{m}$ in the calculation has led to very small changes in the flame length; it probably stems from the effect of secondary drop breakup.

Variant 2. The calculation was made at the pressure in the research chamber $P_{0}=56.3$ bar and mixture ratio $K_{m}=0.31$. This calculation was made to 


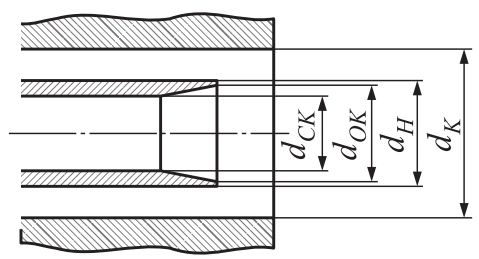

(a)

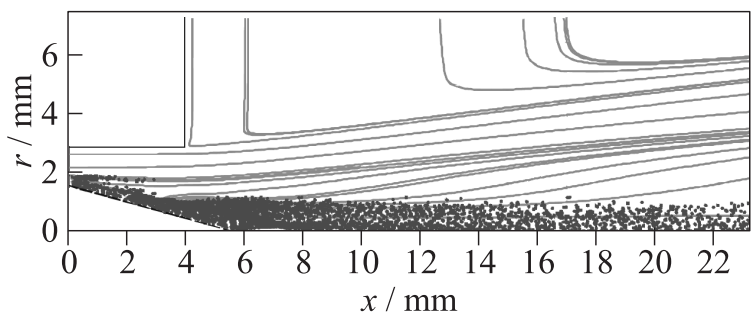

(b)

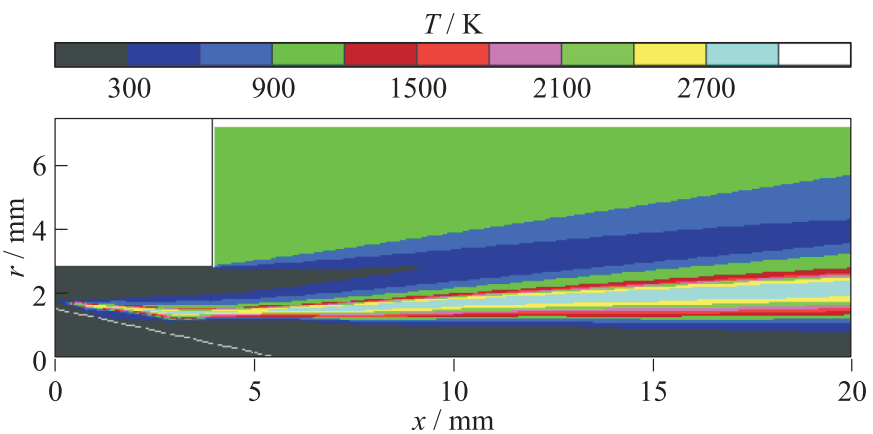

(c)

Figure 1 Variant 1: $(a)$ injector; $(b)$ calculated gas-phase streamlines and droplet trajectories; and $(c)$ temperature field at the near-nozzle region. (Refer Kalmykov et al., p. 187.)

find out the reasons of the abnormal flame shape which recorded in the experiment in the Mascotte research chamber [8] (Fig. 3b). The predicted gas-phase streamlines and temperature field are presented in Fig. $3 a$. In this case, the near-axis recirculation zone forms at the distance $70-115 \mathrm{~mm}$ from the injector exit which is not typical for coaxial-jet injectors. This recirculation zone leads to mixing process intensification and widening of the end part of the flame. It is worth noting that the calculated temperature distribution agrees well with the results of the flame visualization in Fig. $3 b$. 

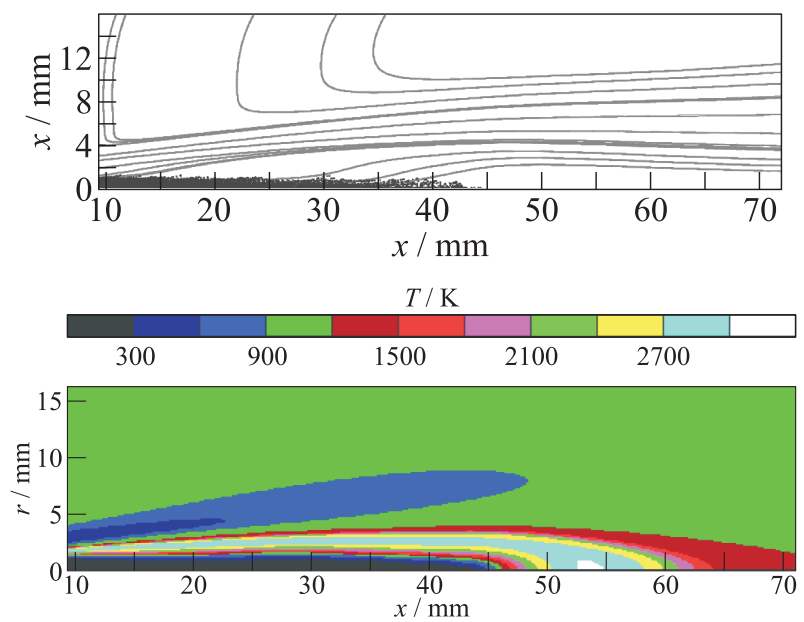

(a)

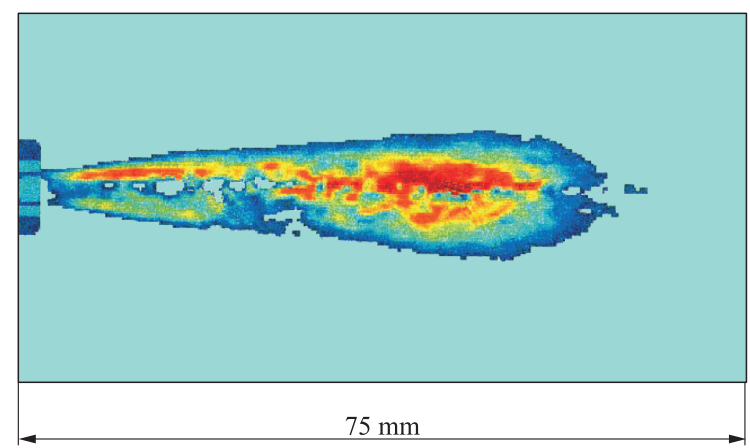

(b)

Figure 2 Injector of variant 1: (a) numerical simulation results: gas-phase streamlines and droplet trajectories and temperature field; and $(b)$ experiment in Mascotte chamber: $\mathrm{OH}^{*}$ emission visualization (ONERA-SNECMA investigation). (Kalmykov et al., p. 188.)

The transverse dimension of the Mascotte chamber comprises $\sim 50 \mathrm{~mm}$. The characteristic distance between injectors mounted on the multiinjector head is as a rule essentially less. Besides, neighbouring jets can have a considerable effect on each other. For evaluating these effects, an additional calculation was conducted. In this calculation, the diameter of the designed element was decreased and the boundary condition of the jet reflection type instead of the solid wall conditions was imposed. This implies that radial derivatives $\partial / \partial r$ were taken equal to zero for all variables except for the velocity radial component, $V$, which was taken 

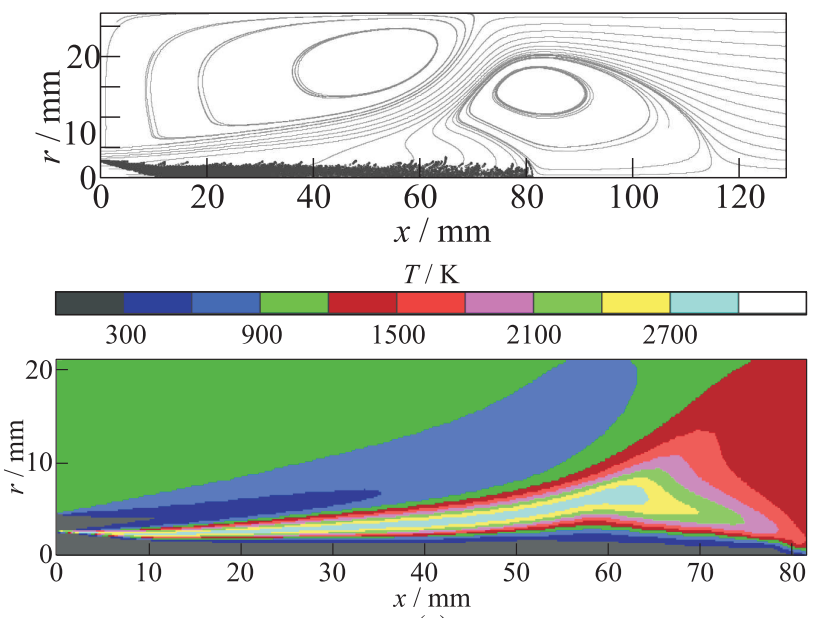

(a)

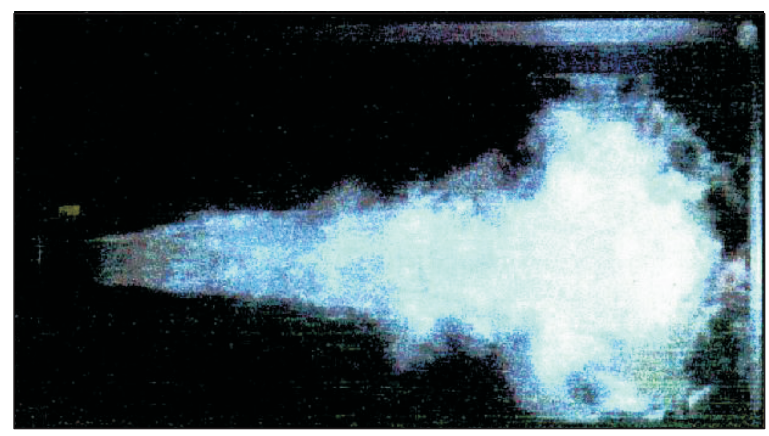

(b)

Figure 3 Variant 2: (a) numerical simulation results: stream lines and droplet trajectories and temperature field; and $(b)$ flow visualization in the Mascotte chamber (ONERA-SNECMA investigation). (Kalmykov et al., p. 189.)

zero: $V=0$. The rest of conditions was the same as for variant 1 . Such boundary conditions are appropriate for calculating the axially symmetric flow in a flow core element in the multiinjector combustion chamber.

The results of calculations are shown in Fig. 4. As is seen, the operation process pattern exhibits essential changes. In particular, the shape of flame has changed and its length (i.e., a distance to a zone of the maximum temperature on the flow axis) has been reduced to $\sim 38 \mathrm{~mm}$. A similar effect has to be taken into account when extending the data obtained in the study of a single injector in the subscale chamber to the conditions in the full-scale multiinjector combustion chambers and gas generators. 


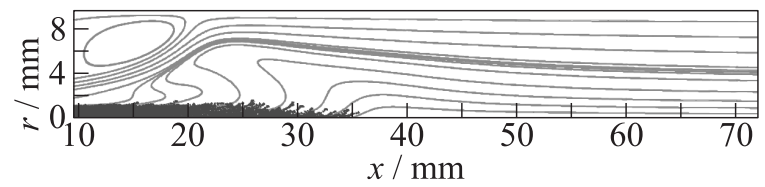

(a)

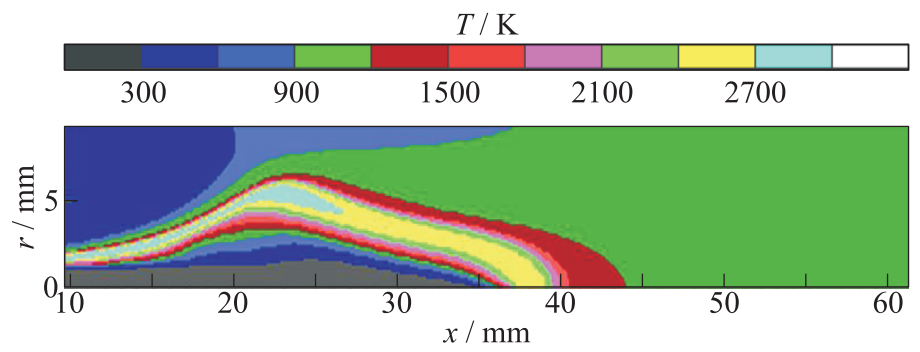

(b)

Figure 4 The results of numerical simulations: $(a)$ stream lines and droplet trajectories, and (b) temperature field. (Kalmykov et al., p. 190.)

\section{FLOW CORE ELEMENT OF COMBUSTION CHAMBER WITH COAXIAL-JET INJECTORS OPERATING IN THE CYCLE OF FUEL-RICH GENERATOR GAS AFTERBURNING}

In the combustion chamber under consideration, injectors similar to those used in the gas generator (see Fig. 1) are applied. Liquid oxygen is supplied through the central cylindrical channel whereas generator gas is supplied through the outer annular channel.

For the basic variant of the injector, the depth of oxygen nozzle, $\Delta H$ $=5.5 \mathrm{~mm}$ and the width of the generator gas channel $d R_{\mathrm{ggch}}=\left(d_{K}-d_{H}\right) / 2$ $=1 \mathrm{~mm}$. The generator gas temperature was set $910 \mathrm{~K}$, the mixture ratio therein was 0.28 , and the pressure in the combustion chamber was taken equal to $8 \mathrm{MPa}$. The mean diameter of droplets in the liquid oxygen spray issuing into the combustion chamber was estimated as $d_{\mathrm{O}_{2}} \leq 0.02 \mathrm{~mm}$ [9]. The axisymmetric grid $\sim 200 \times 80$ was used.

For elucidating the effect of some structural features of injectors of this type on the operation process in the combustion chamber, the following injector modifications were studied numerically: $(i)$ the width of the generator gas channel was increased to $d R_{\text {ggch }}=1.3 \mathrm{~mm}$ (variant 2 ); (ii) the width of the generator gas channel was reduced to $d R_{\text {ggch }}=0.7 \mathrm{~mm}$ ( variant 3 ); and (iii) the oxygen nozzle depth was taken zero, i.e., $\Delta H=0$ (variant 4 ). 
Variant 1 (baseline). In this variant, the depth of oxygen nozzle, $\Delta H$ $=5.5 \mathrm{~mm}$, and the width of the generator gas channel $d R_{\mathrm{ggch}}=1 \mathrm{~mm}$.

In this case, the velocity of generator gas outflow from the injector annular channel is $U_{\text {ogg }} \sim 240 \mathrm{~m} / \mathrm{s}$. The flow pattern in the near-nozzle region is shown in Figs. $5 a$ and $5 b$. The near-axis section of the flow core element is occupied by sprayed oxygen. The flame is stabilized in the zones of reverse flows adjacent to oxygen nozzle edges. Downstream of the edges between the oxygen and methane streams, the narrow high-temperature zones are formed. Due to combustion in the injector channel, the maximum gas velocity at the chamber inlet $(x=0)$ slightly increases and attains $\sim 260 \mathrm{~m} / \mathrm{s}$ and $\sim 30 \%$ of oxygen evaporates thereat. At the periphery of the element, a toroidal recirculation zone about $14 \mathrm{~mm}$ long, adjacent to the chamber bottom, is formed. It envelopes the generator gas jet issuing from the injector. The reverse flow velocity in this zone attains $50 \mathrm{~m} / \mathrm{s}$. It is seen from the figures that in the peripheral recirculation zone, gas-phase composition is characterized by a considerable fuel excess (mixture fraction $\varphi_{\text {per }} \approx 0.7$ and $K_{\text {per }} \sim 0.43$ ) and by a relatively low temperature $\left(T_{\text {per }} \sim 1050 \mathrm{~K}\right)$. Note that the stoichiometric ratio $K_{\text {st }}=4$ is equivalent to $\varphi_{\text {st }}=0.2$ and the composition with $K<K_{\text {st }}$ corresponds to condition $\varphi>\varphi_{\text {st }}$. The region of the reverse flow surrounding the stream of sprayed oxygen and located at a distance $\sim 10$ to $20 \mathrm{~mm}$ from chamber bottom was of particular interest. It is caused by a powerful ejection effect of the high-speed generator gas jet on gaseous oxygen formed due to droplet vaporization. In this region, the local temperature maximum is attained. Distributions of mixture fraction and temperature (Figs. $5 c$ and $5 d$ ) allow one to monitor the progress of propellant mixing and burnout in volume of the flow core element in the combustion chamber. Mixing of oxygen and methane generator gas and propellant burnout proceed with a high rate, so that at a distance $x \sim 250-300 \mathrm{~mm}$, the distributions of $\varphi$ and $T$ over the designed element cross section become uniform enough.

The integral efficiency of the operation process in the combustion chamber can be characterized by a curve of losses of the characteristic velocity, $C^{*}$, along the chamber length. The profiles of losses (Fig. 5e) allowing the evaluation of different flow sections and integral losses, $C^{*}$, (Fig. $5 f$ ) are most representative for the analysis of the operation process efficiency. As is seen, at distances $x>250 \mathrm{~mm}$, the losses $C^{*}$ are extremely low; in the near-axis and middle parts of the flow $(r \sim 0-6 \mathrm{~mm})$, the losses $C^{*}$ are positive; and at the periphery $(r \sim 7-$ $9 \mathrm{~mm})$ the losses are negative. The integral losses $C^{*}$ in the flow core element attain $0.6 \%$ to $0.7 \%$ at the length of the combustion chamber of $200 \mathrm{~mm}$.

Variant 2 (wide channel of generator gas). In this variant, the depth of oxygen nozzle $\Delta H=5.5 \mathrm{~mm}$ and the width of the generator gas channel $d R_{\text {ggch }}=1.3 \mathrm{~mm}$.

In this case, the velocity of generator gas outflow from the injector annular channel is less than in the baseline variant: $U_{\text {ogg }} \sim 175 \mathrm{~m} / \mathrm{s}$. The flow pattern 


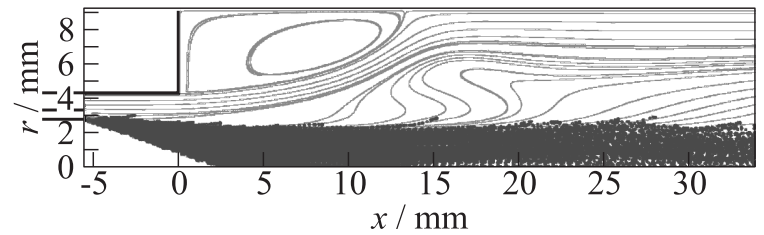

(a)

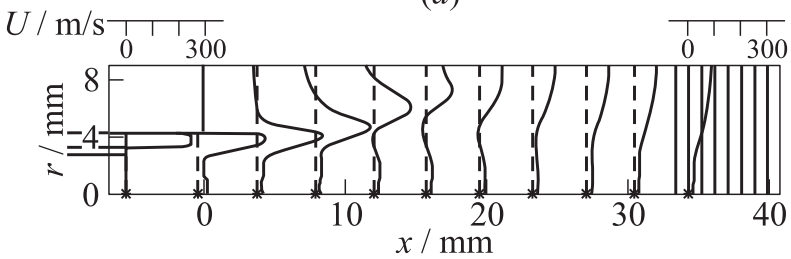

(b)
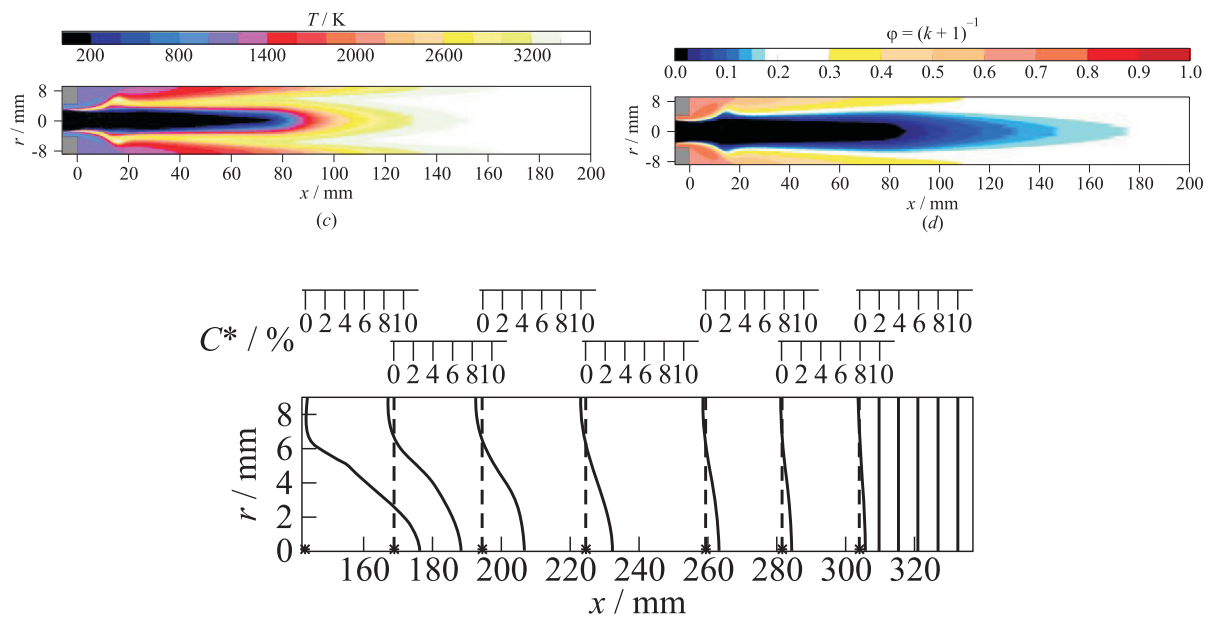

(e)

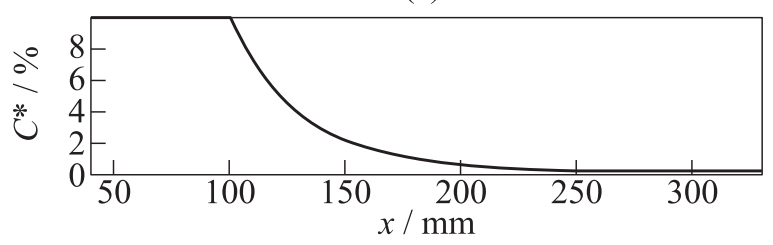

$(f)$

Figure 5 The results of numerical simulation, variant $1, \Delta H=5.5 \mathrm{~mm}$ and $d R_{\text {ggch }}$ $=1 \mathrm{~mm}$ : (a) gas-phase streamlines and droplet trajectories; (b) axial velocity profiles; $(c)$ temperature field; $(d)$ the field of mixture fraction; $(e)$ losses profiles, the final section; and $(f)$ integral losses as a function of chamber length. (Kalmykov et al., p. 192.) 
in the near-nozzle region is shown in Figs. $6 a$ and $6 b$. The peripheral recirculation zone has the same sizes as in the baseline variant, but the maximum velocity of the reverse flow decreased to $\sim 30 \mathrm{~m} / \mathrm{s}$, whereas the fuel concentration increased $\left(\varphi_{\text {per }} \approx 0.75, K_{\text {per }} \sim 0.34\right)$ and the temperature decreased to $T_{\text {per }} \sim 900 \mathrm{~K}$. These values are indicative of a decrease in the mixing rate of oxygen and methane in the near-nozzle region as compared to the baseline variant. This is mainly associated with the decrease in the turbulence intensity and effective turbulent transport coefficients, as well as with weakening of secondary aerodynamic breakup of oxygen droplets.

Propellant mixing and burnout proceed slower, and therefore, the distributions of composition and temperature over the element cross section exhibit more nonuniformity than in the baseline variant (Figs. $6 c$ and $6 d$ ). The profiles of losses of the characteristic velocity, $C^{*}$, are presented in Fig. 6e. The integral losses $C^{*}$ in the flow core element (Fig. $6 f$ ) attain $1.2 \%$ at the length of the chamber of $200 \mathrm{~mm}$.

Variant 3 (narrow channel of generator gas). In this variant, the depth of oxygen nozzle $\Delta H=5.5 \mathrm{~mm}$ and the width of the generator gas channel $d R_{\text {ggch }}=0.7 \mathrm{~mm}$.

In this case, the velocity of generator gas outflow from the injector annular channel is higher than in the baseline variant: $U_{\text {ogg }} \approx 355 \mathrm{~m} / \mathrm{s}$. The flow pattern in the near-nozzle region is shown in Figs. $7 a$ and $7 b$. A peripheral recirculation zone has the same sizes as in the baseline variant of the injector, but the maximum velocity of the reverse flow increased to $\sim 60 \mathrm{~m} / \mathrm{s}$, the fuel concentration decreased $\left(\varphi_{\text {per }} \approx 0.65, K_{\text {per }} \sim 0.54\right)$, and the temperature increased to $T_{\text {per }} \sim 1150 \mathrm{~K}$. These values indicate an increase in the mixing rate of oxygen and methane in the near-nozzle region as compared with the baseline variant. This is mainly caused by an increase in the turbulence intensity and effective turbulent transport coefficients, as well as by strengthening of secondary aerodynamic breakup of oxygen droplets. Downstream of the injector nozzle, propellant mixing proceeds more intensely, so that the distributions of mixture fraction and temperature over the element cross section are more uniform than in the baseline variant (Figs. $7 c$ and $7 d$ ). The corresponding loss profiles are given in Fig. 7e. The integral losses $C^{*}$ in the flow core element (Fig. $7 f$ ) comprise $0.4 \%$ at the combustion chamber length of $200 \mathrm{~mm}$.

Variant 4 (oxygen nozzle depth is zero: $\Delta H=0$ ). In this variant, the width of the generator gas channel $d R_{\text {ggch }}=1 \mathrm{~mm}$.

In this case, the velocity of generator gas outflow from the injector annular channel is identical to the baseline variant: $U_{\text {ogg }} \sim 240 \mathrm{~m} / \mathrm{s}$. The flow pattern in the near-nozzle region is shown in Figs. $8 a$ and $8 b$. A peripheral recirculation zone has the same sizes and the reverse-flow maximum velocity is the same as for the baseline variant, but fuel concentration in this zone increased $\left(\varphi_{\text {per }} \approx 0.74\right.$, $K_{\text {per }} \sim 0.35$ ), while the temperature decreased to $T_{\text {per }} \sim 900 \mathrm{~K}$. These values 


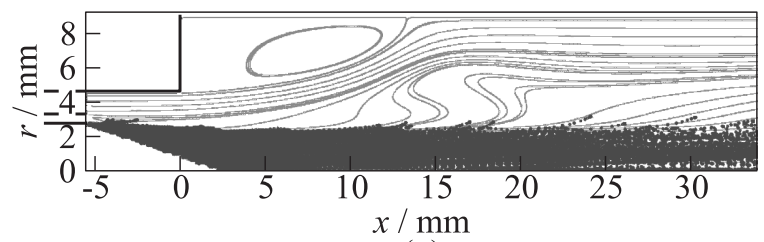

(a)

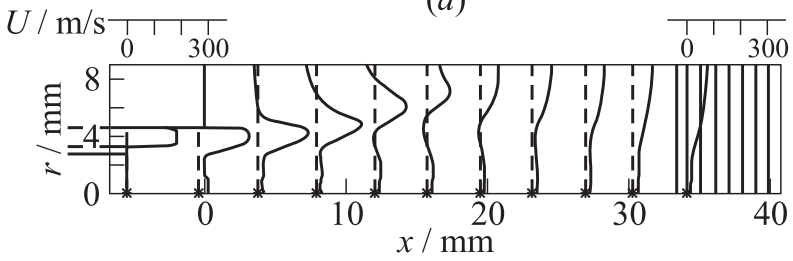

(b)
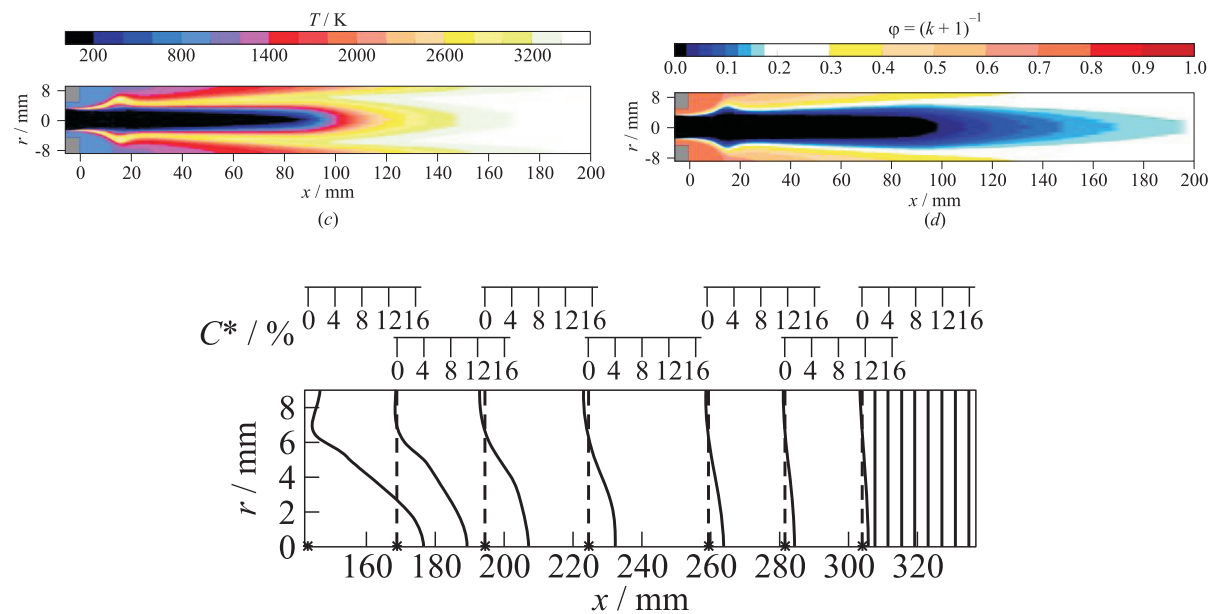

(e)

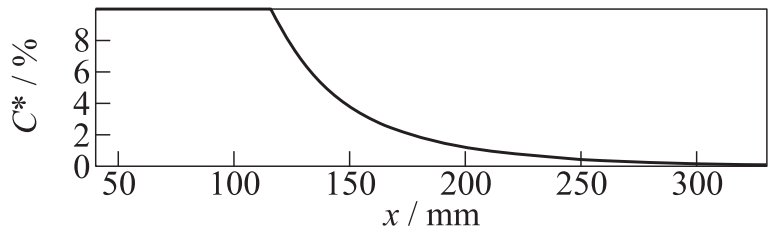

$(f)$

Figure 6 Numerical simulation results, variant $2, \Delta H=5.5 \mathrm{~mm}$ and $d R_{\text {ggch }}$ $=1.3 \mathrm{~mm}$ : (a) gas-phase streamlines and droplet trajectories; $(b)$ axial velocity profiles; $(c)$ temperature field; $(d)$ the field of mixture fraction; $(e)$ losses profiles, the final section; and $(f)$ integral losses as a function of chamber length. (Kalmykov et al., p. 194.) 

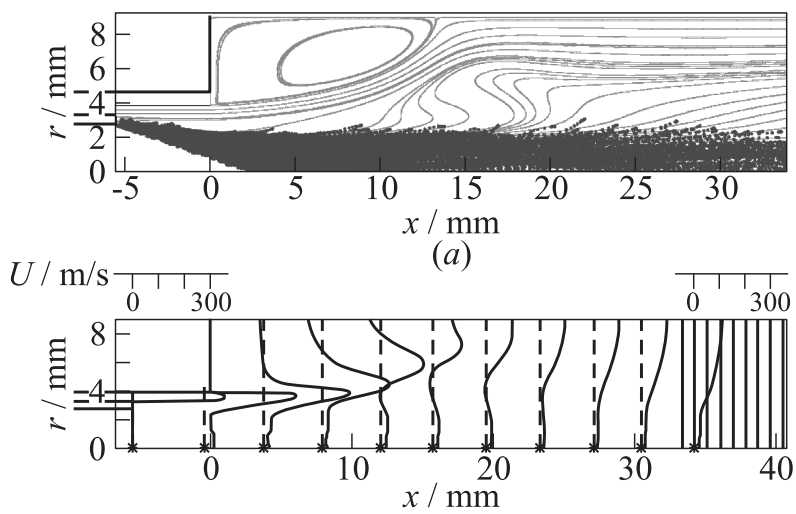

(b)
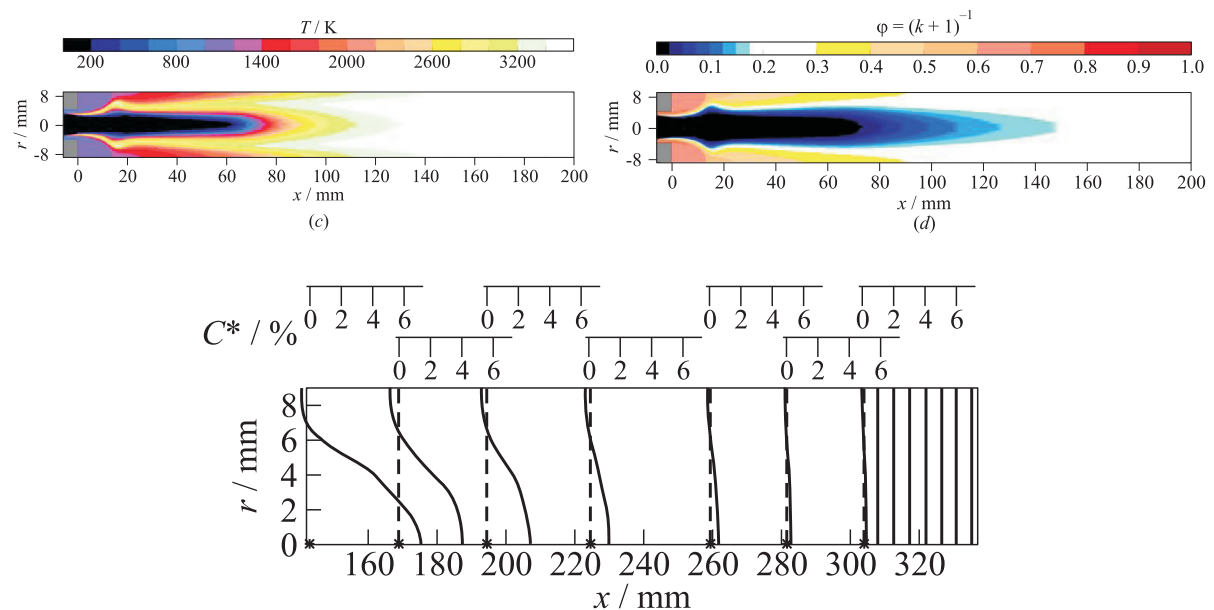

(e)

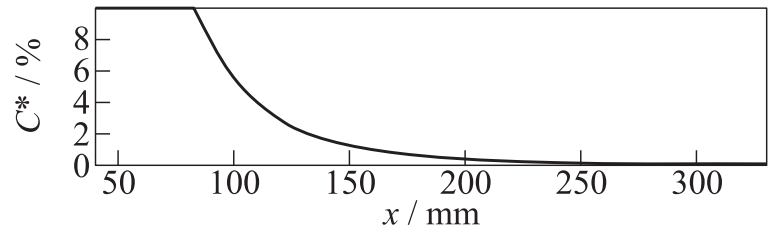

$(f)$

Figure 7 Numerical simulation results, variant $3, \Delta H=5.5 \mathrm{~mm}$ and $d R_{\text {ggch }}$ $=0.7 \mathrm{~mm}$ : (a) gas-phase streamlines and droplet trajectories; $(b)$ axial velocity profiles; $(c)$ temperature field; $(d)$ the field of mixture fraction; $(e)$ losses profiles, the final section; and $(f)$ integral losses as a function of chamber length. (Kalmykov et al., p. 195.) 

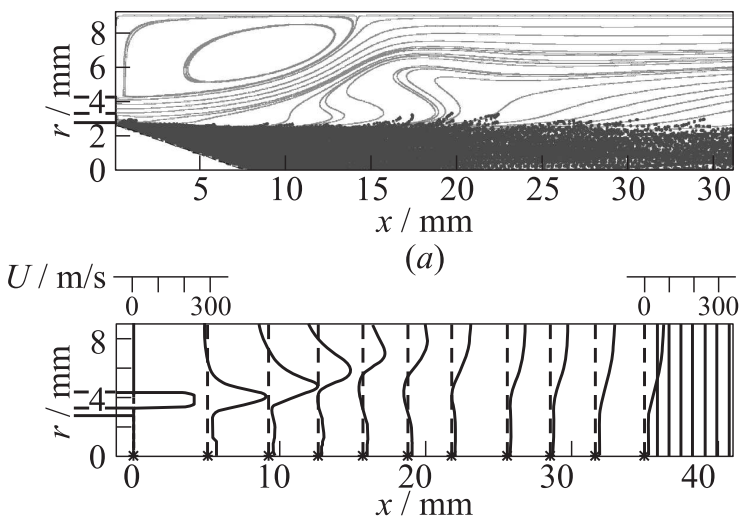

(b)
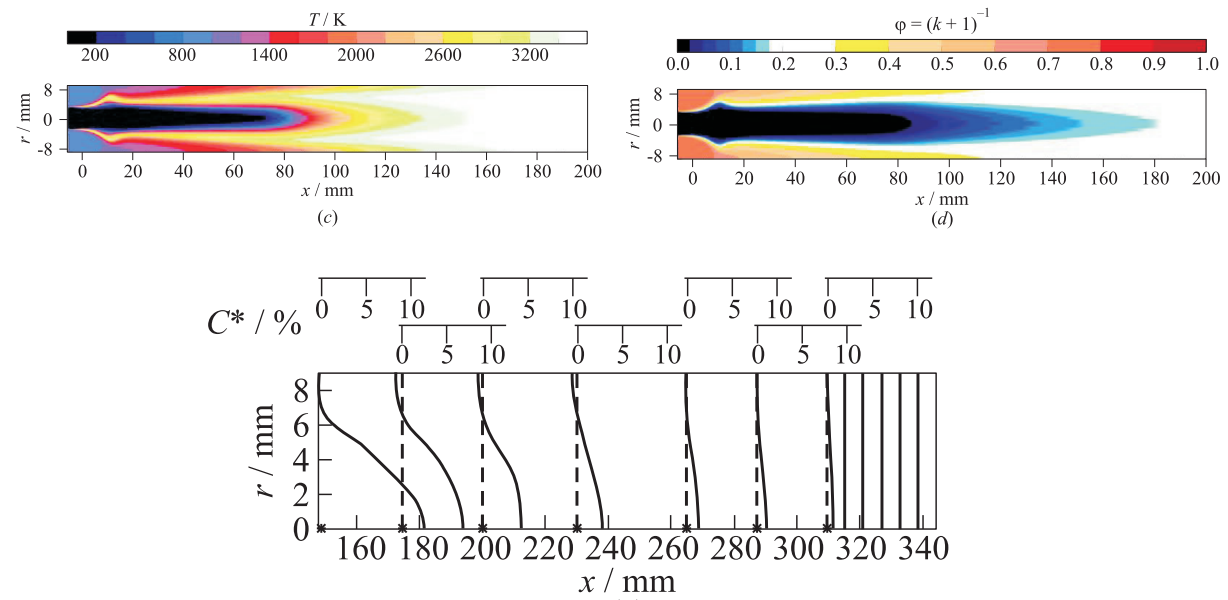

$(e)$

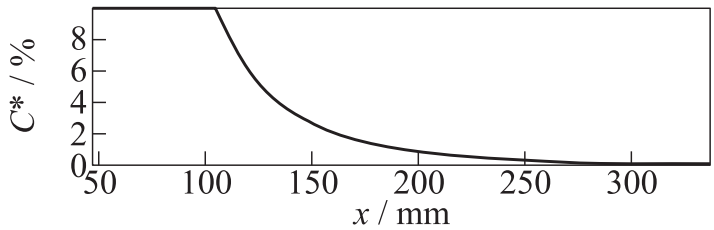

$(f)$

Figure 8 Numerical simulation results, variant $4, \Delta H=0$ and $d R_{\text {ggch }}$ $=1 \mathrm{~mm}$ : (a) gas-phase streamlines and droplet trajectories; $(b)$ axial velocity profiles; $(c)$ temperature field; $(d)$ the field of mixture fraction; $(e)$ losses profiles, the final section; and $(f)$ integral losses as a function of chamber length. (Kalmykov et al., p. 196.) 
imply a decrease in the mixing intensity of oxygen and methane in the near-nozzle region as compared to the baseline variant. This results mainly from the absence of propellant premixing and burning in the injector channel. Downstream the near-nozzle region, the distributions of composition and temperature over the element cross section are somewhat more nonuniform than in the baseline variant (Figs. $8 c$ and $8 d$ ). The profiles of the characteristic velocity losses, $C^{*}$, are shown in Fig. $8 e$. The corresponding integral losses $C^{*}$ in the flow core element comprise $0.8 \%$ at the combustion chamber length of $200 \mathrm{~mm}$.

\section{COMBUSTION CHAMBER WITH IMPINGING-JET INJECTORS}

Considered in this section is the combustion chamber with the pressure of about 10 bar. Two variants of the injector head have been studied.

Variant 1. In this variant, the injector head of the combustion chamber (Fig. 9) with monopropellant main injectors of "impinging-jet" type (doublet injectors for methane and triplet injectors for oxygen) is considered. The injectors are arranged in concentric circles with alternating rings of methane and oxygen supply. In the near-axis region and on baffles, methane jet injectors are used. The mixture ratio for this chamber is $K_{m}=3.36$.

All calculations were conducted in axisymmetric approximation for the cylindrical combustion chamber. The grid of size $\sim 200 \times 350$ was used.

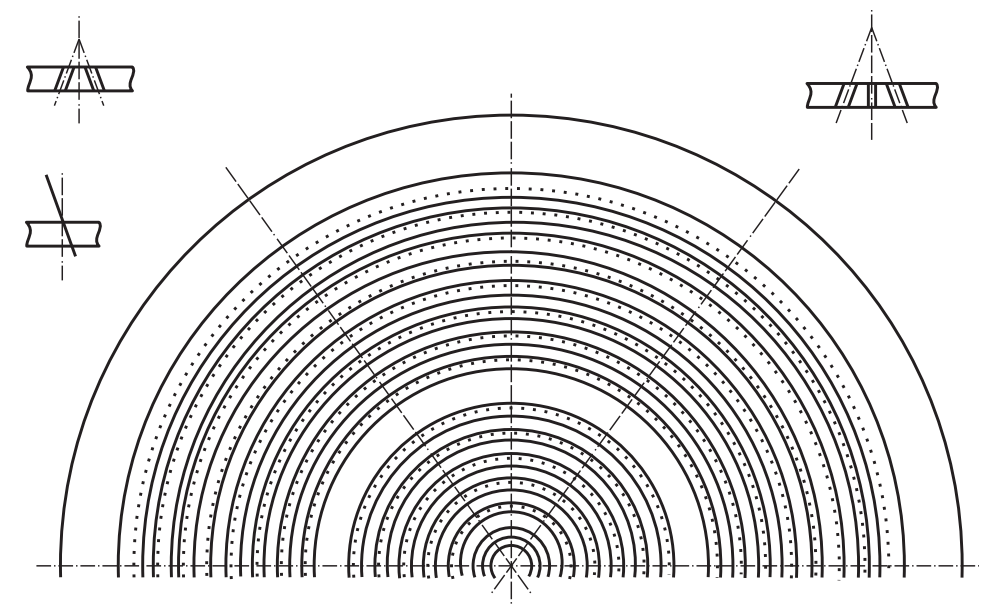

Figure 9 Injector head scheme 
It was assumed that propellant droplets form upon impingement of sprays, and prior to a time of the impingement, the sprays do not interact with gas phase. The parameters of droplets after propellant spraying (effective diameters and angles of divergence) were determined from experimental correlations [9]. Initial effective mean diameters of $\mathrm{LOX}$ and $\mathrm{CH}_{4}$ droplets were estimated as $d_{\mathrm{O}_{2}}=0.155 \mathrm{~mm}, d_{\mathrm{CH}_{4}}=0.1 \mathrm{~mm}$.

Consider the main specific features of the operation process at the nearbottom region of the combustion chamber (Fig. 10). Impingement and spraying of fuel streams occur at a distance of about $7 \mathrm{~mm}$ from the chamber bottom, and those of oxidizer streams at about $14 \mathrm{~mm}$. Thus, fuel sprays start evaporating and actively interacting with gas-phase closer to the bottom than the oxidizer sprays. The gas temperature near the bottom varies mainly from about 900 to $1500 \mathrm{~K}$. In the neighborhood of fuel streams, larger recirculation zones are formed than near the oxidizer streams. These zones facilitate a transfer of both fuel droplets and oxidizer-rich gas to the chamber bottom from downstream.

At a distance of about $15 \mathrm{~mm}$ where the formation and evaporation of oxidizer drops come into effect, small recirculation zones with a near-stoichiometric composition and high temperature are generated around oxidizer streams. Downstream these zones, between the fuel and oxidizer streams, the regions of stoichiometric composition with elevated gas temperatures and velocities are formed. These regions, on the one hand, promote drops breakup and evaporation and gas turbulization (and, therefore, mixing intensification in the gas phase) but on the other hand, prevent mutual penetration of fuel and oxidizer drops.

Due to a larger specific flow rate, the central ring of fuel sprays has the enhanced ejection capacity and draws in the gas with a higher $K$ from the adjacent oxidizer streams more actively. This results in the growth of gas temperature near the bottom at $r \approx 20 \mathrm{~mm}$.

As for operation process near the ring baffle, the following can be noted.

The fuel streams nearest to the ring baffle eject the oxidizer-rich gas from the space between oxidizer streams and the baffle. As a result, in the neighborhood of the root section of the baffle, the zones with stoichiometric composition and high temperature are formed.

The chamber part, exterior as viewed from the ring baffle, has a higher specific fuel flow rate than the interior part. Therefore, the gas flow from the chamber exterior part expands slightly downstream of the baffle into the interior part. Gas carries oxygen drops along but actually does not change the direction of nondisintegrated liquid fuel sprays outflowing from the baffle endface. This causes a small displacement of a zone with high oxygen drop concentration, that is formed on rendezvous of oxygen streams at the exterior and interior sides of the baffle, relative to fuel streams outflowing from the baffle. A trace of this displacement is well noticeable downstream on the profiles of $\varphi$ and $C^{*}$. 


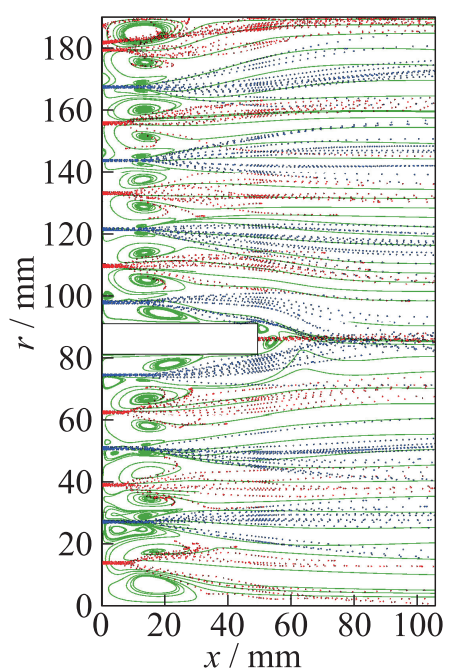

(a)

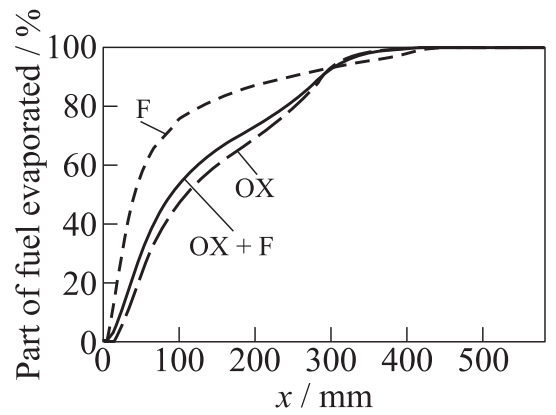

(c)

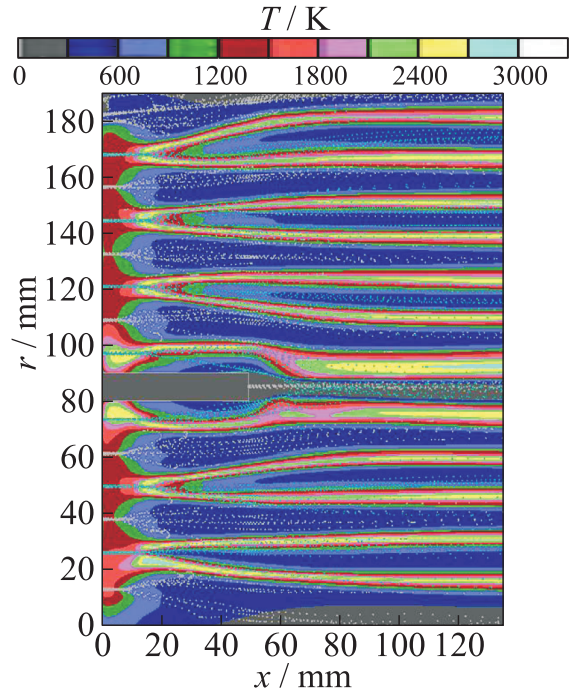

(b)

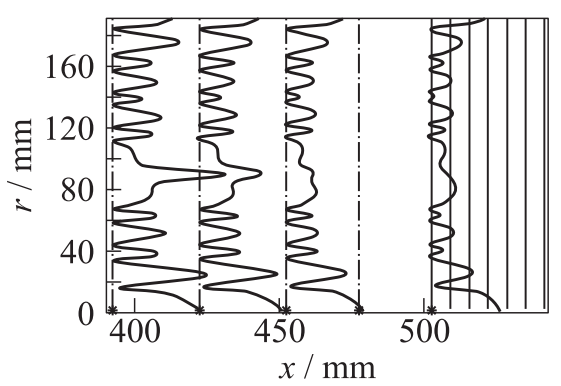

(d)

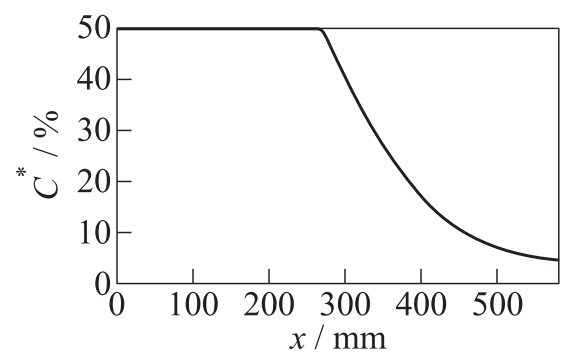

(e)

Figure 10 Numerical simulation results, monopropellant injectors: $(a)$ gas-phase streamlines and droplet trajectories; $(b)$ temperature field; $(c)$ part of fuel evaporated; $(d)$ losses profiles; and $(e)$ losses $C^{*}$ with the chamber length. (Kalmykov et al., p. 199.) 
The gas flow along the wall in the near-bottom region consists mostly of methane and has a low temperature.

The temperature field is extremely nonuniform in the near-bottom and middle sections of the chamber but downstream the cross section $x \approx 300 \mathrm{~mm}$, where more than $90 \%$ of propellant has evaporated, the propellantf mixing and burning start proceeding more intensely.

In respect to the analysis of the operation process efficiency over the chamber cross section, the profiles of mixture fraction, $\varphi=1 /(K+1)$, and losses $C^{*}$ are most representative and allow evaluating the contributions of different flow cross sections into the integral losses. As is seen from Figs. $10 d$ and $10 e$, the level of losses, $C^{*}$, is rather large over the whole chamber cross section. The maximum losses are associated with the streams issuing from near-axis and near-wall injectors, as well as from injectors in the region of the baffle. At the cross section $x \approx 500 \mathrm{~mm}$, the losses are large in those parts of the flow core which correspond to centers of oxygen streams and are minimal in the vicinity of centers of methane streams. The main reason for the high average level of losses is the strong nonuniformity of the composition caused by noncompleteness of gasifiedpropellants mixing along the chamber. The calculated value of losses, $C^{*}$, comprises about $7.5 \%\left(K_{m}=3.36\right)$ at the combustion chamber length of about $500 \mathrm{~mm}$.

To elucidate the influence of droplets initial diameter on the operation process, a calculation was carried out at increased diameters: $d_{\mathrm{O}_{2}}=0.178 \mathrm{~mm}$ and $d_{\mathrm{CH}_{4}}=0.285 \mathrm{~mm}$. The losses $C^{*}$ increased by $\sim 1 \%$.

A weak decrease in the operation process efficiency with increasing the initial drop diameters may be attributed to the following reason. The rate of aerodynamic drop deformation in the gas flow increases with drop diameter. Therefore, the larger the drops, the higher the influence of their secondary breakup in the near-bottom region of the combustion chamber which results in drop atomization.

A series of calculations with variable parameters of fuel streams was performed to elucidate the specific features of mixture formation in the scheme with monopropellant injectors on impinging jets. The following main results were obtained.

The increase in angles of divergence of drops at points of jet impingement and spraying intensifies mutual penetration of divergent clusters of fuel and oxidizer drops and results in more uniform mixing of propellants in the near-bottom region, and accordingly, in the growth of the combustion efficiency.

The decrease in drop diameter, on the one hand, decreases the evaporation time, but, on the other hand, lowers the flight distance of drops clusters in the lateral direction and deteriorates mixing of propellants in the form of drops in the near-bottom region. As a result, the total effect on the operation process efficiency can be both positive and negative depending on the specific initial drop parameters. 
Variant 2. To reduce a degree of incomplete combustion of propellants in the combustion chamber, it has been proposed to replace the monopropellant injectors with bipropellant injectors (Fig. 11).

When using the injector assembly of this design, the operation process pattern in the flow core sufficiently far from the near-wall region must be periodic with respect to radial coordinate. Therefore, the computational domain was limited by the minimum value of the radial coordinate $r_{0}=108 \mathrm{~mm}$ with imposing a periodical boundary condition at $r=r_{0}$. In the calculation of integral characteristics of the operation process (curves of burnout and losses of the characteristic velocity), the region $0<r<r_{0}$ was also taken into account. The value of mixture ratio in the chamber was taken equal 3.5.

It was assumed that the propellant spraying to droplets occurs upon the impingement of jets, and prior to the impingement, the jets do not interact with gas phase. As for the base injectors of the core, it was believed that upon the impingement of fuel and oxidizer jets, the drops of methane and oxygen were distributed uniformly across the spray. Parameters of drops upon propellant spraying (effective diameters and angles of divergence) were determined from empirical relationships [9].

For the injectors in the core, the impingement and spaying of fuel and oxidizer jets occur at a distance of about $15 \mathrm{~mm}$ from the chamber bottom. Near the chamber bottom, between jets, the recirculation zones assisting in flame stabilization are formed. The impingement and spraying of jets in the near-wall row take place at a distance of about $4 \mathrm{~mm}$ from the chamber bottom which is much less than that for injectors in the core. Thus, the ejection capacity of near-wall jets near the bottom is essentially larger than that of core jets. This results in partial overflow of the hoter gas from the core to the near-wall region over the bottom surface.

As is seen, even in the case of uniform distribution of fuel and oxidizer drops across the spray cone upon the impingement of jets, a noticeable nonuniformity of gas-phase composition and temperature arises in the flow core in the combustion chamber. It is attributed mainly to the difference between evaporation rates of methane and oxygen. Methane drops evaporate comparatively rapidly and gaseous methane strives for a uniform distribution over the chamber cross section. Oxygen evaporates much slower in the near-bottom region and the clusters of its drops remain in the flow for a longer time and produce regions with high concentrations of gaseous oxygen. Composition and temperature nonuniformities in the chamber remain considerable even at the end section of the chamber, but they are essentially less than those in the variant with monopropellant injectors (variant 1). The distributions of quantities characterizing the losses $C^{*}$ over the flow cross section in the combustion chamber are shown in Fig. 11e. Maximum losses appear in the near-wall region and the zones with high oxidizer concentrations in the flow core. The calculated value of losses $C^{*}$ at the combustion chamber length of about $500 \mathrm{~mm}$ comprises about $3.5 \%$ (at $K_{m}=3.5$ ). 


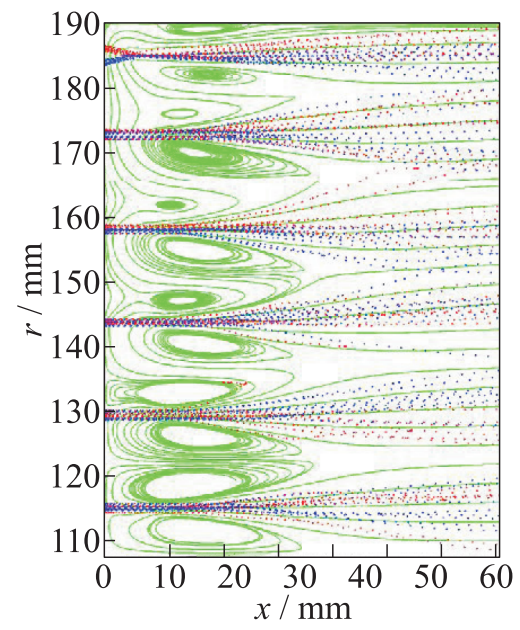

(a)

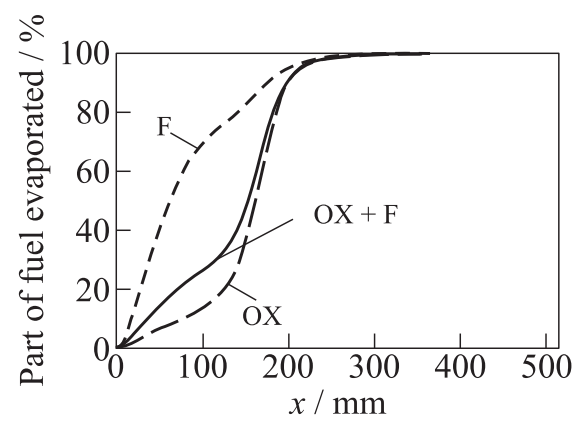

(c)

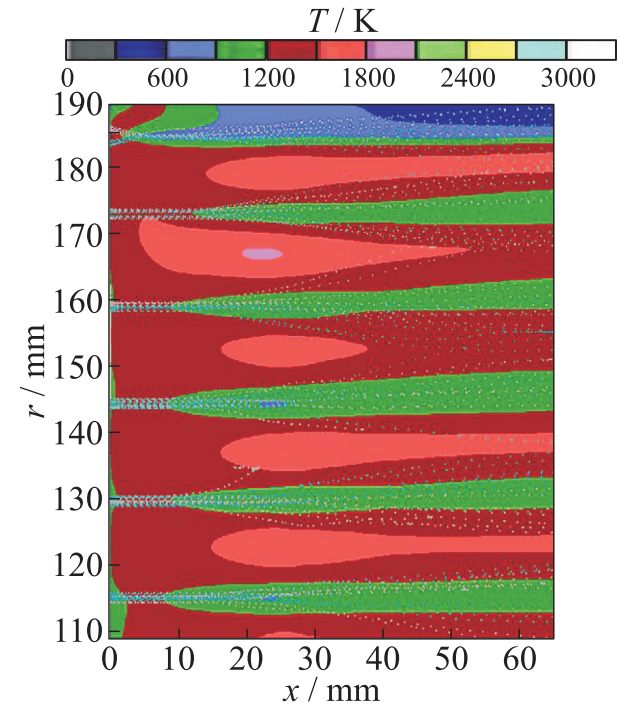

(b)

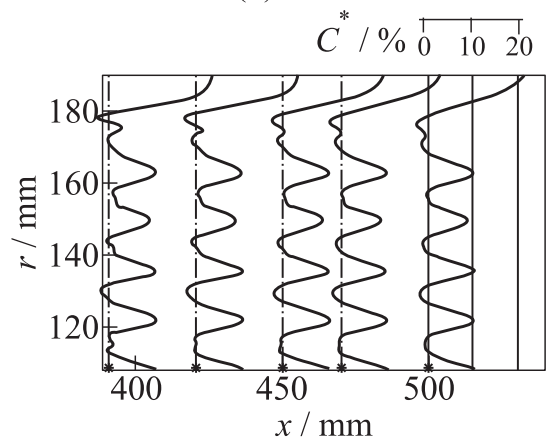

(d)

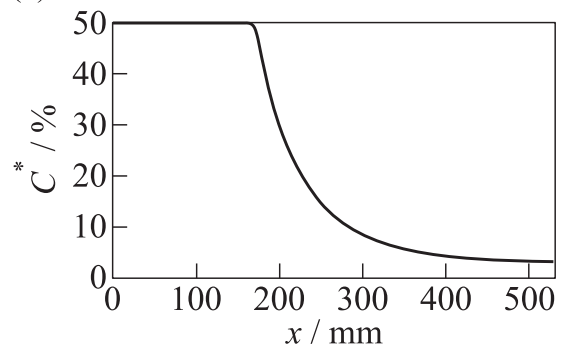

(e)

Figure 11 Numerical simulation results, bipropellant injectors: $(a)$ gas-phase streamlines and droplet trajectories; $(b)$ temperature field; $(c)$ part of fuel evaporated; $(d)$ losses profiles; and $(e)$ losses $C^{*}$ with the chamber length. (Kalmykov et al., p. 202.) 
Worth noting is one specific feature of mixture formation in the chamber with bipropellant impinging-jets injectors. As in this case spraying of fuel and oxidizer occurs at an identical distance from the chamber bottom and drop evaporation rates depend heavily on their initial diameter, the mixture ratio and temperature near the bottom are much more sensitive to the relation between the diameters of fuel and oxidizer drops at the point of jet spraying.

\section{CONCLUDING REMARKS}

Numerical simulation has proved to be a good tool for calculating mixing and combustion in gas generators and combustion chambers of oxygen-methane engines. Gas generators with two variants of coaxial-jet injectors have been considered. A conventional regime of flow and combustion is realized in the nominal mode for the first variant of the injector. The second variant gives an unusual flow regime with central reverse flow and sharp expansion of the end part of the flame for the coaxial-jet injector. Formation of the central reverse flow intensifies mixing of oxygen and methane jets and leads to substantial flame shortening. Despite the second injector variant has the diameter of one half of the first one, the flame length has increased only insignificantly. The calculated temperature fields in both variants correspond well to the results of experimental flame visualization.

The calculations of the operation process in the combustion chamber with coaxial-jet injectors for the engine operating in the cycle with fuel-rich generator gas afterburning have been also performed. The width of the generator gas channel and depth of oxygen nozzle were varied in the calculations to study the effect of some structural features of injectors on the operation process in the combustion chamber. The injectors of this type were shown to provide high combustion efficiency in the chamber.

The calculations of the operation process in the combustion chamber with monopropellant and bipropellant injectors of the impinging-jet type have been also performed. The processes of propellant evaporation, mixing, and combustion have been analyzed. The propellant combustion completeness has been evaluated.

\section{REFERENCES}

1. Kalmykov, G.P., A. A. Larionov, D. A. Sidlerov, and L. A. Yanchilin. 2005. Numerical simulation of the working process in gas generator working on propellant components LOX + gaseous methane. 1st EUCASS Conference. Moscow. 
2. Pantankar, S. 1980. Numerical heat transfer and fluid flow. New York: Hemisphere Publ. Corp.

3. Gosman, A. D., and E. Ioannides. 1981. Aspects of computer simulations of liquidfuelled combustors. AIAA Paper No. 81-0323.

4. Habiballah, M., L. Vingert, J. C. Traineau, and P. Vuillermoz. 1996. MACOTTE: A test bench for cryogenic combustion research. 47th Astronautical Congress (International). Beijing, China. IAF-96-S.2.03.

5. Vingert, L., M. Habiballah, and J.C. Traineau. 1999. MASCOTTE: A research test facility for high pressure combustion of cryogenic propellants. 12th Aerospace Conference (European). Paris, France.

6. Haidn, O. J., and M. Habiballah. 2003. Research on high pressure cryogenic combustion. Aerospace Sci. Technol. 7:473-91.

7. Singla, G., P. Scouflaire, C. Rolon, and S. Candel. 2005. Transcritical oxygen/transcritical or supercritical methane combustion. Proc. Combustion Institute 30:2921-28.

8. $\mathrm{LOX} / \mathrm{CH}_{4}$ gas generator - ONERA/KeRC/SNECMA/CNES. 2003. Compte rendu de reunion DEFA/L-No. 028/03.

9. Dityatkin, Yu.F., L.A. Klyachko, B. V. Novikov, and V.I. Yagodkin. 1977. Liquid spraying. Moscow: Mashinostroenie Publ. 